\title{
Rules at Play: Correcting Projectable Violations of Who Plays Next
}

\author{
Hanna Svensson ${ }^{1}$ (D) Burak S. Tekin ${ }^{1,2}$
}

Accepted: 5 June 2021 / Published online: 21 September 2021

(c) The Author(s) 2021

\begin{abstract}
This study examines the situated use of rules and the social practices people deploy to correct projectable rule violations in pétanque playing activities. Drawing on Ethnomethodology and Conversation Analysis, and using naturally occurring video recordings, this article investigates socially organized occasions of rule use, and more particularly how rules for turn-taking at play are reflexively established in and through interaction. The alternation of players in pétanque is dependent on and consequential for the progressivity of the game and it is a practical problem for the players when a participant projects to break a rule of "who plays next". The empirical analysis shows that formulating rules is a practice for indicating and correcting incipient violations of who plays next, which retrospectively invoke and establish the situated expectations that constitute the game as that particular game. Focusing on the anticipative corrections of projectable violations of turn-taking rules, this study revisits the concept of rules, as they are played into being, from a social and interactional perspective. We argue and demonstrate that rules are not prescriptions of game conduct, but resources that reflexively render the players' conducts intelligible as playing the game they are engaging in.
\end{abstract}

Keywords Ethnomethodology and conversation analysis · Social interaction · Rules · Games · Correction · Projectability

\section{Introduction}

This paper focuses on players' practices for correcting violations of a basic rule concerning the alternation of players in the game pétanque. In difference from work conceiving rules as external regulations that are followed and pre-determine social conduct, this study is situated within an approach treating rules as normative orders

Hanna Svensson

hanna.svensson@unibas.ch

1 Department of Linguistics and Literature, University of Basel, Maiengasse 51, CH-4056 Basel, Switzerland

2 Present Address: Ankara Yıldırım Beyazıt University, Ankara, Turkey 
whose relevance is constituted by their use in situated ways. In this tradition, rules are intrinsic to the very intelligibility of social conduct (Coulter 2009; Garfinkel 1967; Sacks 1992; Wittgenstein 1958). In his paper on trust as a condition for concerted action, Garfinkel (1963) examines the use and relevance of basic rules-or constitutive expectancies - in games, and demonstrates how these observations are relevant for understanding how people intelligibly engage in everyday social activities. Basic rules make up the constitutive order of events that provides for the recognizability of a particular activity and share three features: (i) they frame a set of alternatives the player expects to choose from; (ii) the player expects that the same set of alternatives are binding upon other players; (iii) the player expects that other players expect from her what she expects from them (1963: 190). To say that a person "trusts" another person is to say that "the player takes for granted the basic rules of the game as a definition of his situation, and that means of course as a definition of his relationships to others" (1963: 194). Acknowledging constitutive expectancies as a requisite for social actions as situated accomplishments motivates the interest in examining the interactional practices participants use to reflexively establish them as intersubjective achievements.

Studies on games in Ethnomethodology and Conversation Analysis (EMCA), takes an interest in them as locally accomplished activities and focus on their orderliness and organizational properties in a wide range of games, including children's games (Goodwin 2006; Sacks 1992), board/card games (Liberman 2013; Livingston 2008, 2012), computer/video games (Bennerstedt and Ivarsson 2010; Tekin and Reeves 2017) and formal games like sports (Kew 1992; Macbeth 2012). The ways in which participants of game activities use rules for playing in publicly available ways by means of interactional resources remain nevertheless understudied (but see Goodwin 1983, 2006; Kew 1986; Livingston 2006).

Sacks points out the relevance of engaging in conduct that is in accordance with rules. Working on children playing games, he observes that players treat the right-wrong aspects of actions while playing as consequential for their acceptability as game moves (1992: 500). Building on the insights provided by Sacks, Goodwin shows that children display a particular sense of rules in their games and that they deploy the rules in a strategic manner to restructure the game outcomes and the related player identities (1985; 1995, 2006). She points out that rules are "constituted through a set of practices that are lodged within a local community engaged in the performance of a particular activity" (Goodwin 1995: 277). Rules and game play mutually elaborate one another: players use rules as a resource to organize their activities and the game provides the environment in which rules gain and collect their meaning and relevance (Liberman 2016). Moreover, rules are typically invoked when a problem occurs and embody efforts to give sense to actions that breach a situated order (Goodwin 2006; Liberman 2016).

While the relevance of detailed empirical analysis for researching rules within the realm of social studies has been settled (Garfinkel 1963; Rawls 2019), people's situated use and publicly available understanding of rules remains understudied. This paper aims to contribute to the research on rules in games by examining the interactional practices amateur players use to establish the rules as 
observable and reportable in and through their practical reasoning about them during game playing. We are interested in players' orientations to the rules concerning taking turns at play, which is an organizational aspect pertaining to most social activities.

In what follows, we introduce the game pétanque through an example of actual play and discuss the relevance of turn-taking organization as an observable, local production of rules at play. The empirical analysis includes two sections: Initially, we provide a systematic examination of how participants correct projectable violations of turn-taking rules in pétanque. Subsequently, we examine how players explicitly address rules as rules in the game. Finally, we discuss the contributions of our analysis for the conceptualization of rules within social sciences.

\section{The Game}

This empirical investigation of rules-in-use draws on a corpus of around $6 \mathrm{~h}$ video recordings of pétanque playing activities in a city in Switzerland. For the purposes of this paper, we concentrate on a sub-corpus of around $1.5 \mathrm{~h}$ of video data recorded in a garden outside a café. Six players in two different game constellations (Werner, Pedro, and Diana playing against Emma, Stefan, Christian; and Diana and Emma playing against Werner and Pedro) engage in playing pétanque, all of whom are more or less regular customers at the café and somehow acquainted with each other. The participants mainly use English as a lingua franca, though they sometimes speak Swiss German, French and Portuguese with certain individuals. In the data, the players report themselves (to each other) to have different degrees of experience concerning playing pétanque. Whereas Werner claims to play every day, Emma claims to have played a few times this summer, while Diana, Pedro, Stefan and Christian claim to be familiar with the game although not having played for a long time.

The following example provides a glimpse of the data, introduces the game, and demonstrates the relevance of turn-taking rules for this game. The example is extracted from a game in which Emma and Diana play against Pedro and Werner. The game material comprises a target ball and twelve throwing balls. Each team has six balls, and each player has three balls. The players throw their balls from a designated throwing circle and the purpose is to position the team's balls closer to the target ball than the other team's balls. After throwing the target ball, the players alternate to throw their balls between and within teams.

The transcriptions follow the conventions developed by Jefferson (2004) and Mondada (2018). Balls that are thrown are indicated in the transcriptions in their relative order within each game (from B1 to B12) and arrows in the screenshots indicate trajectories of the thrown balls and the participants. A square indicates the target ball and black dotted and solid circles around the participants and the thrown balls are added to differentiate the different teams. White dotted circles indicate details of particular interest in the screenshots. In the following extract, we join the action as Emma throws the first ball in the game, after having thrown the target ball. 

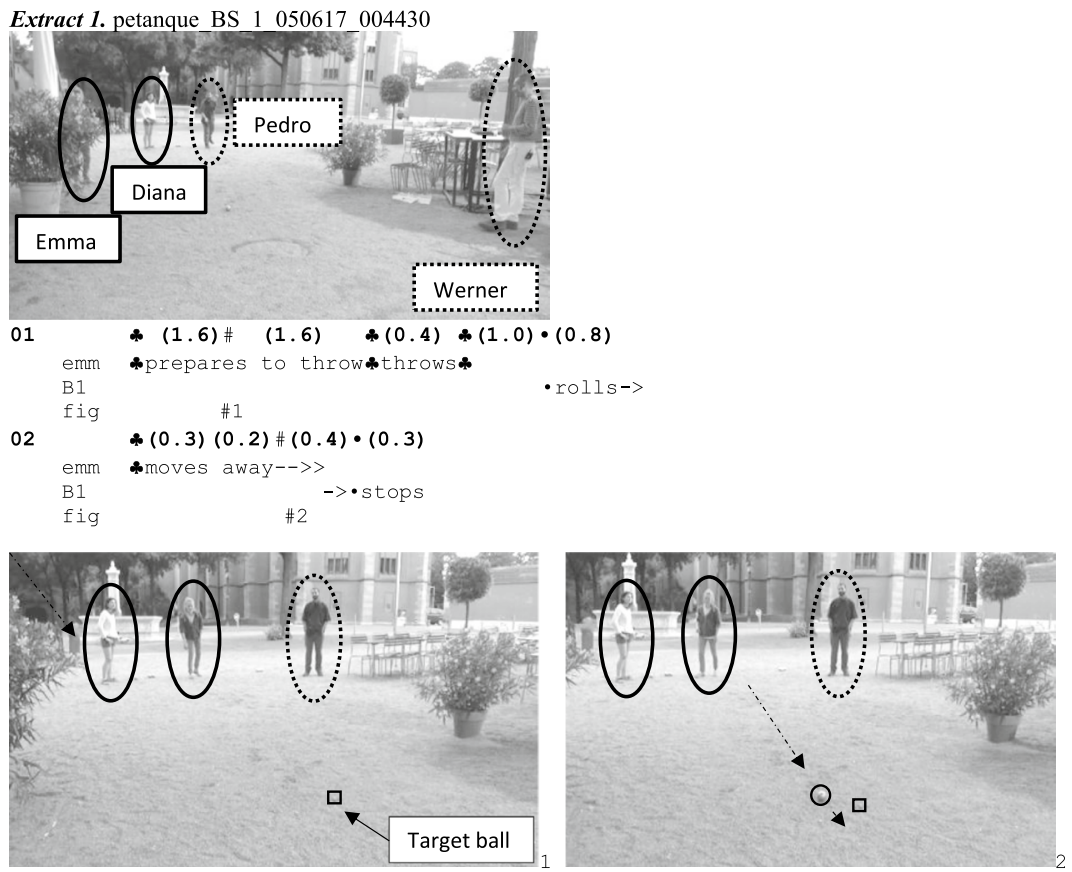
03 WER yes not that $\nabla$ ba: $[: d$
ped $\quad \nabla$ turns and moves to his right-->
04 EMM [not that $\mathrm{ba} \nabla: \mathrm{d}$ eh
ped
$->\nabla$ kneels down and grabs a ball-->
05 $(0.7) \nabla(0.1) \#(0.4)$
ped $\quad$ Dstraightens his body and moves towards throwing circle-->
fig $\# 3$
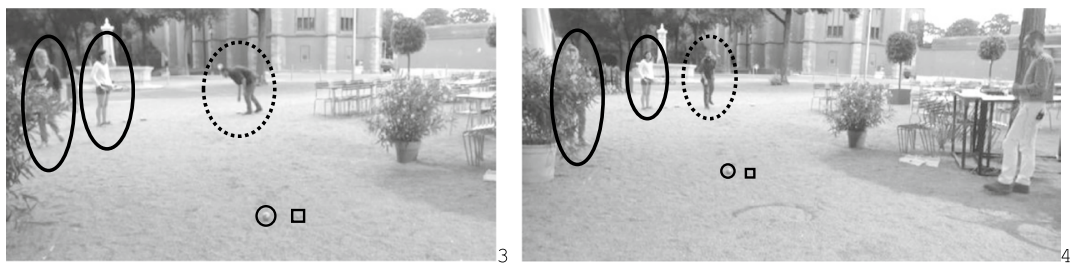
06 EMM i have seen wor $\nabla$ se euh
07
ped
(0.1)
08 WER yes (.) Vdid you
ped $\quad->$ Vprepares to throw-->
$(0.2)$
EMM yes (.) e[uh: baguettE:
WER [hahahahaVhahahaV
ped $\quad->\nabla$ throws $\nabla$
12
$(0.2) \#(0.4) \cdot(1.0)$

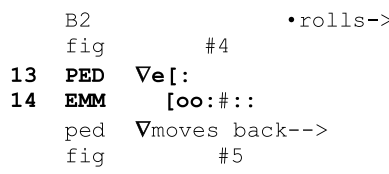



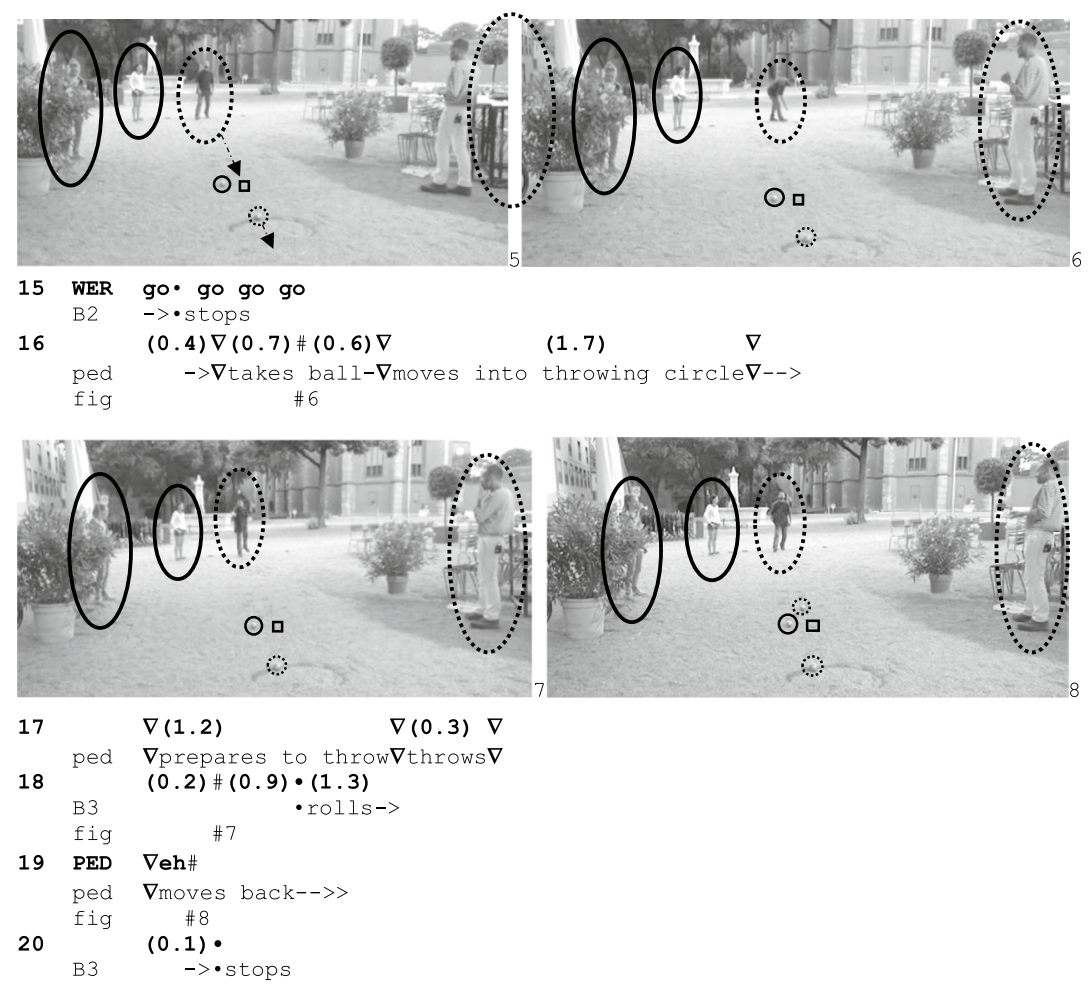

The game rules as we formulate them here are not exogenous descriptions of the game pétanque, but draw on the analysis of the participants' observable conduct when playing. Players organize their game conduct as recognizably sharing the seen but unnoticed features that reflexively produce the game rules as a situated accomplishment.

Emma throws her ball from the throwing circle (1, figure 1) and moves away even before her ball has stopped (2, figure 2), orienting to the relevance of team and player change. Pedro manifestly orients to the same relevance as he turns to his right, grabs a ball from the ground and moves into the throwing circle - projecting to play next.

The first ball in the game will be the closest one to the target ball. In this way, the two players organize the player change in such a way that they constitutively produce the rule that the team that is not the closest to the target ball plays.

As Pedro throws his first ball $(3-11$, figures 3,4$)$ and it rolls, both Pedro and Emma produce response cries $(13,14)$, and Pedro begins to move out of the throwing circle, projecting that he will not play again (14, figure 5). In doing this, Pedro either displays that his throw will result in being the closest to the target ball (implying team change), or that his teammate Werner will play next 
(implying team continuation). However, as the outcome becomes clearer, Werner produces repeated imperatives to Pedro to continue (15). By orienting to the relevance of team continuation, he tacitly treats the throw as not good enough (that is, not closer to the target ball than Emma's prior ball), while establishing a local order of taking turns at play within his team. Pedro aligns with this by taking another ball, stepping back into the throwing circle (16, figure 6) and making another throw (17-18, figure 7. The second ball is closer to the target ball than Emma's ball and Pedro leaves the throwing circle (19, figure 8).

The participants in this data play in teams, where the alternation of players is dependent on and consequential for the progressivity of the game. The order of players is not fixed, but locally established and contingent on (the outcome of) each throw in the game. Therefore, the question of who plays next is a recurrent, practical problem for the participants. After a throw, the team that is then closer to the target ball waits and the team with balls that are further away from the target ball plays. When all the balls are thrown, the team having the closest ball to the target ball wins the game, gaining one point per ball that is closer to the target ball than the losing team's ball(s). This implies that one team might end up throwing all their balls in one "turn," while the other team can play them at the end without risk of interference by the other team. In this respect, the alternation of players allows for progressing in the game, but it also embodies and reflects the current situation in the game. Players taking turns is a constitutive aspect of the game, and indicative of the players' situated understanding of how the game is expected to unfold. Team/player continuation, or change, after the completion of a throw, is projectable and accomplished by the current/next players as they stay in, leave and move towards the throwing circle. These embodied resources and trajectories have spatial-temporal features that are publicly available, enabling players to monitor and treat their respective conducts as playing according to the rules. The witnessable order of taking turns at play is thus locally accomplished, constituting and being treated as done in accordance with rules for next-player-ship, which is contingent on the outcome of each throw.

While progressively projected next-player-ship can be tacitly accepted, it can also be corrected when it projects to violate a rule, sometimes involving references to rules of who plays next. As Garfinkel points out, "[f]or the person who seeks to comply with the constitutive order of play, an action - and it need only be one - that breaches the basic rules is incongruous in a particular way and its occurrence violates the game as an order of activities" (1963: 196, italics in original). In this way, amateur pétanque playing activities represent a perspicuous setting (Garfinkel and Wieder 1992) for investigating socially organized occasions of rule use as the games unfold (Garfinkel 1963, 2019; Goodwin 2006; Liberman 2013), and more particularly how rules for turn-taking at play are reflexively established by embodied social practices in and through interaction. 


\section{Turn-taking and Rules}

Turn-taking is a fundamental organizational feature of various aspects of social life, and its formal properties are intrinsic to the social contexts they configure and significant for their recognizability (Sacks, et al. 1974). In conversational activities, who speaks next is a recurrent practical problem for the participants. The solution to this problem is manifested in the continuous succession of speakers. Each speaker-change thus displays the participants' understanding of what a prior action has made relevant next. Actions gain their intelligibility by virtue of their accountable relevance with reference to previous actions, and the understanding of the conditional relevance set up by an action is displayed in what happens next (Schegloff and Sacks 1973: 297f.). In this way, turn-taking is a situated manifestation of intersubjectivity as a procedural accomplishment, owing to the sequential organization of social interaction, progressing over time. By collaboratively managing the issue of when to change speaker and who speaks next, participants display their local, reciprocal understanding of what is going on in the situated activities they engage in (Moerman and Sacks 1988: 83).

Sacks (1992) points out that the specific sequential organization of playing activities, such as opening and closing actions and initiating and responding to moves, is a fundamental feature of recognizably engaging in game playing. The retrospective and prospective aspect of each move, or turn, furnishes the possibilities and constraints concerning what do to next (Goodwin 1985; Livingston 2006). Furthermore, Sharrock and Dennis argue that the procedural or operational aspect of rules concerns "the question of understanding what is involved in following a rule, where following a rule is a matter of "taking the next step"' (2008: 9).

When a problem of understanding what is relevant to do next in an interaction emerges, participants repair this (Schegloff 1992; Schegloff et al. 1977). Corrective practices emerge in environments where normative orders are broken, thus dealing with natural breaches of constitutive expectancies, and they are fundamental for solving troubles of intersubjectivity. In this way, the examination of repair and correction is significant for studying the use of rules as an interactional accomplishment. Other-initiated corrections open up a side sequence and replace what is depicted as an inadequate aspect of the ongoing activity with an alternative (Jefferson 1972; Svensson 2020). Corrections of natural language are done by means of replacing alternatives, and the identification of the trouble source is done by proposing its solution. Furthermore, activities involving participants' entire bodies, imply specific spatial and temporal features regarding the projectability of their visible and inspectable trajectories (Svensson 2017; Tekin 2019).

In pétanque, which is played with the entire body, the organisation of player alternation is central for the progressivity of the game. Moreover, who plays next is dependent on and consequential for the strategic and thus competitive aspects of the game, retrospectively embodying the players' advancements until-that-point, rendering transparent the current state of the game as well as its prospective (and strategic) features. When the normative organization of turn-taking is breached, participants deploy correcting practices for coming to terms with the trouble. As players correct projections of next-player-ship or even retracts turns-at-play, they reflexively establish the rules for player alternation as basic rules in the game pétanque. 


\section{Correcting Projectable Rule Violations}

In what follows, we will look at the organization of player alternation by examining embodied manifestations of next-player-ship, and corrections of projectable violations of rules for who plays next. While the constitutive expectancies regarding player alternation are observable in the seen but unnoticed features of the players' game conduct, corrective sequences are particularly revealing with regard to the participants' practical reasoning about rules, as they orient to deviation from routine play as a locally achieved normative order. As noted above, each throw in the game makes another throw relevant next until all balls are thrown. Looking at all relevant places for player change, the collected instances include sequences where the players use corrective practices for managing emerging problems of player change. The examples presented here are considered emblematic of our understanding and discussion of the situated production of rules at play.

The following extract is taken from the beginning of a new game. Stefan, Emma and Christian play against Diana, Pedro and Werner. Stefan has already thrown the target ball, and we join the action as he prepares to throw the first ball into the game from the throwing circle:

Extract 2. no it's them BOUL $050617 \quad 00.16 .30$

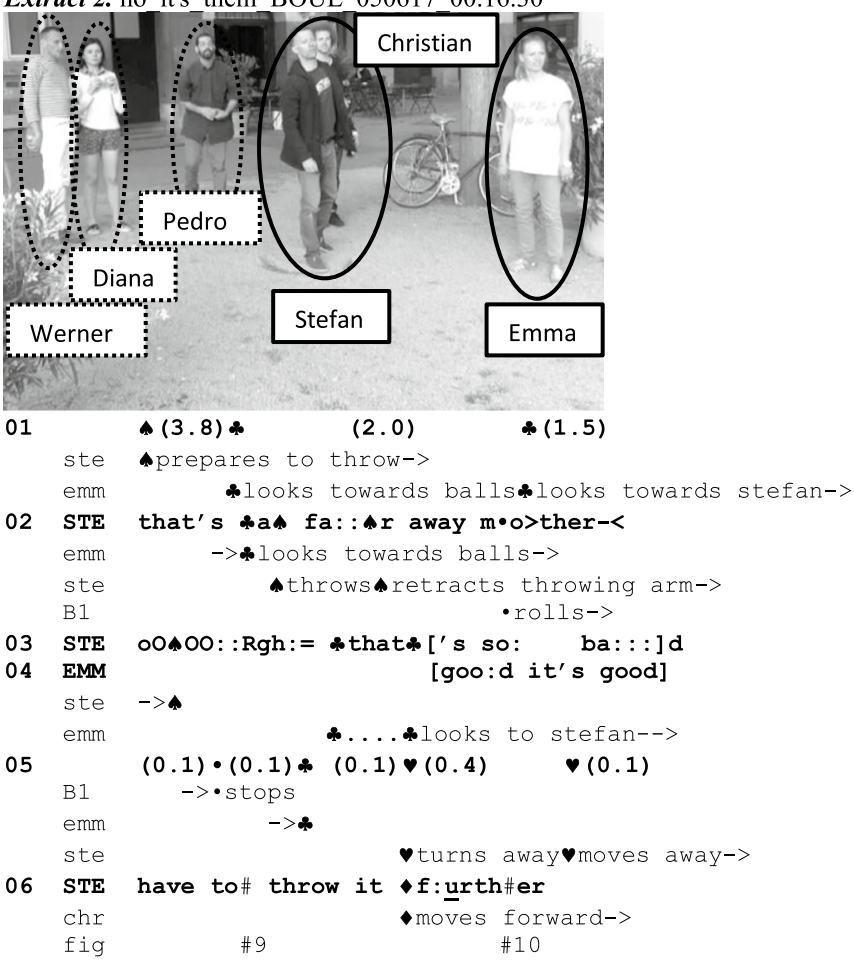



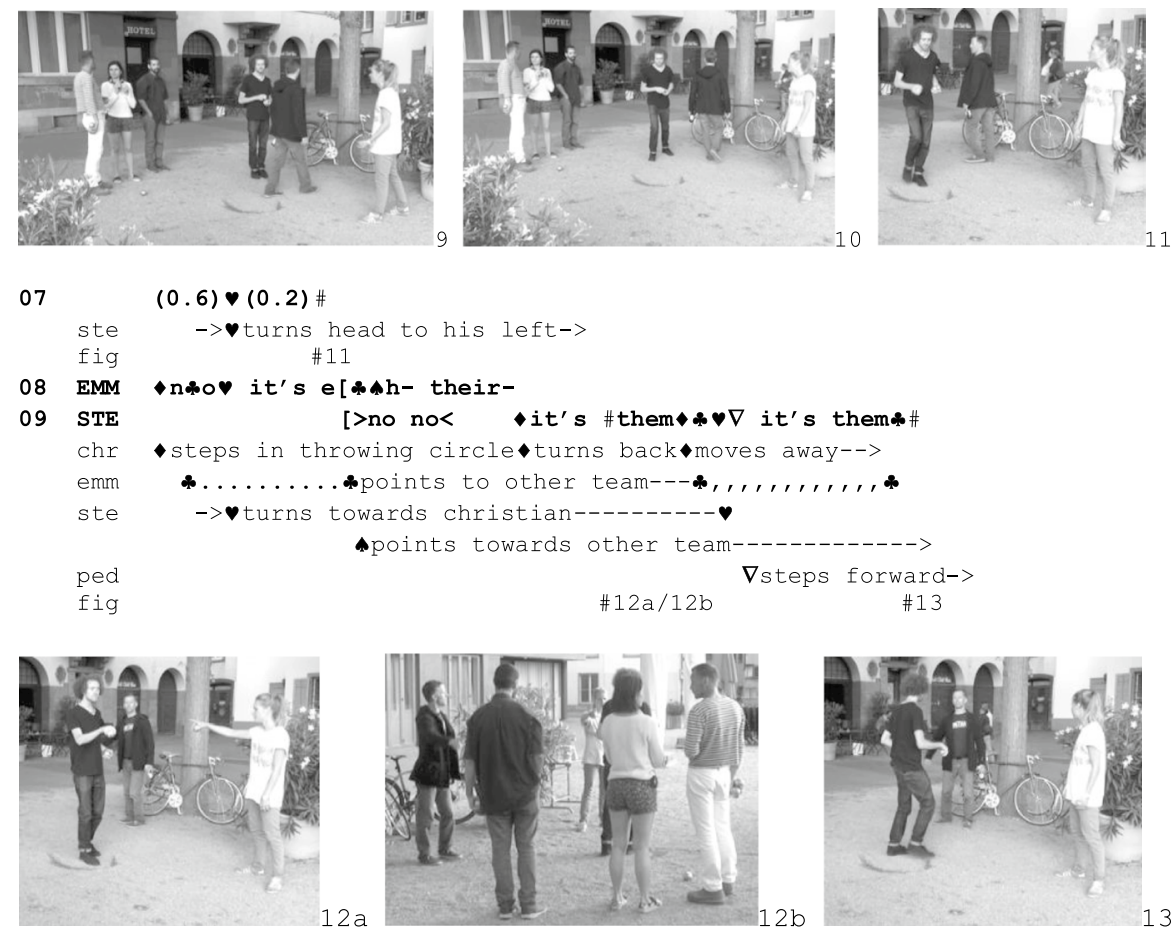

10

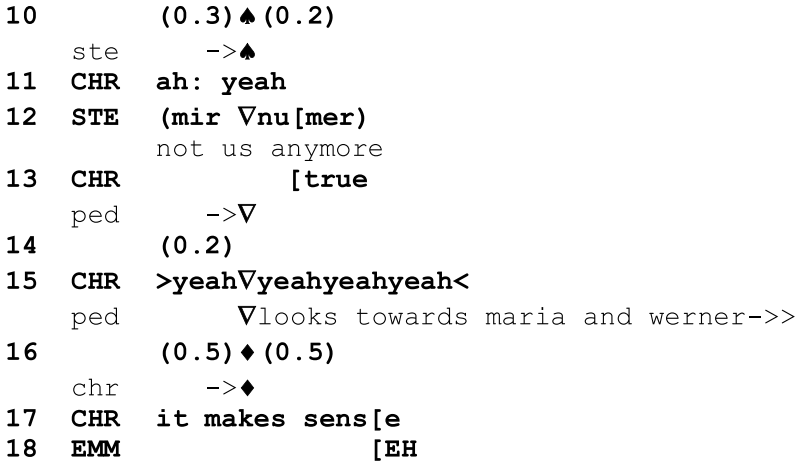

As Stefan prepares to make his throw, he formulates the distance to the target ball as "far away" (2), assessing the difficulty to make a good throw and anticipating a poor outcome. Keeping his position in the throwing circle and monitoring the ball in motion, allows him to progressively evaluate the emerging outcome through a response cry which is transformed into a negative assessment: "that's so: ba:::d" (3), which his teammate Emma counters in overlap (4). As this is the first ball in the game it is, naturally, the closest ball to the target ball (see Extract 1), signifying team change, according to the rule that the team closer to the target ball 
doesn't play. As Stefan moves away from the throwing circle, marking the completion of his turn in the game (5, figure 9), he nevertheless produces yet another assessment, characterizing his play performance as not good enough (6). Leaving the throwing circle also makes it available for potential next players to step in, and as Stefan leaves, his teammate Christian, holding his balls in his hands, walks towards the throwing circle, projecting to play next (6, figure 10). In this way, the players reflexively establish the throwing circle as a constitutive feature of the game, which configures the environment as a game space where players' conduct is recognizable as moves in the game as they take turns at play, one at a time (see Sacks et. al. 1974). As Christian walks towards the throwing circle, both Stefan and Emma visibly monitor Christian's trajectory (figure 11). While he steps in the throwing circle, both Emma and Stefan treat this as projecting to break a rule of who-plays-next. Emma produces a "no," and states that "it's eh- their-" (projecting "turn") while pointing to the other team (8, figure 12a). Stefan produces a " $>$ no no $<$ " in overlap and states that "it's them it's them," also pointing to the other team (9, figure 12b). While the negative polarity markers reject Christian's displayed understanding of him being a legitimate next player (see Goodwin 2011), the references to the other team indicate the solution to the problem.

Christian recognizes and aligns with Emma's and Stefan's corrections as concerning his projection of next-player-ship by turning back, moving away from the throwing circle (9, figure 13), and producing a change of state token ("ah: yeah," 11). Although Christian has already left the throwing circle, Stefan produces an additional formulation of his correction in a negative format, which retrospectively marks the other team's turn to play next as being related to the end of their team's turn ("mir numer"; "not us anymore," 12). Christian's subsequent confirmation tokens $(13,15,17)$ retrospectively claim an understanding of the reasoning behind the corrections. By invoking its "truth" (13), he claims to have the knowledge to assess whether his previously projected next-player-ship corresponds to a relevant rule that is applicable to this specific situation in the game. Moreover, by formulating that "it makes sense" (17), he explicitly acknowledges the rationality of the rule, with regard to the game procedures that it invokes. As such, he claims an understanding of his previous course of action as projecting to break a basic rule, which is consequential for how the game should progress. Furthermore, not only Christian but also Pedro recognizes and acknowledges the corrections by stepping towards the throwing circle, projecting to play next and applying the relevant turntaking rule. This also shows that Emma's and Stefan's respective turns $(8,9)$ are heard as making relevant that one player from the other team should play next. In this way, participants reflexively establish the constitutive expectancies that make the game in which (i) players make their throws from the throwing circle, (ii) one player plays at a time, (iii) players take turns in the game, (iv) the completion of a throw can make player change relevant, and (v) player change is contingent on the outcome of each throw.

In the next extract, Pedro and Werner play against Diana and Emma. Diana and Emma threw the first ball in the game, which is still the closest ball to the target ball. We join the interaction as Pedro throws the fourth ball in the game, which is also his last ball, while his teammate Werner has not played yet. 
Extract 3. you didn't check the rules BOUL 050617_00.45.18
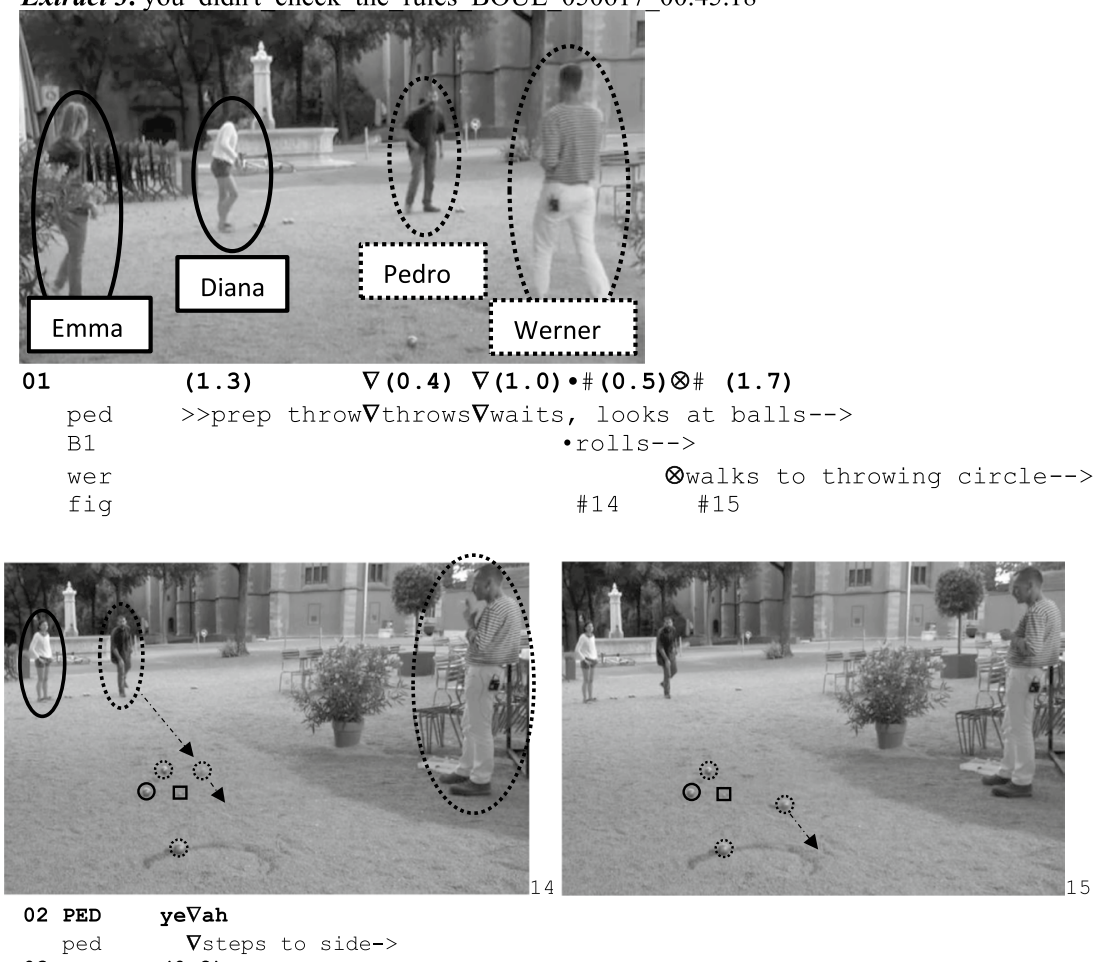

03 (0.2)

04 PED it (should be) $-\nabla$

ped
$(0.1) \cdot(0.8) \bullet(0.5)$
$->\nabla$ moves back to the side-->
$\bullet(2.1) \diamond \div(0.2)$
$\leftrightarrow(1.6) \leftrightarrow(0.1) \oplus(0.5)$ $->\cdot$ stops

B1

emm

emm

fig

06 EMM

näse\#

- lks down takes balls moves to circle prep to throw-->

+looks to werlooks to dia-->>

emm

fig

no

$->$ points to ped;wal-->

\# 17
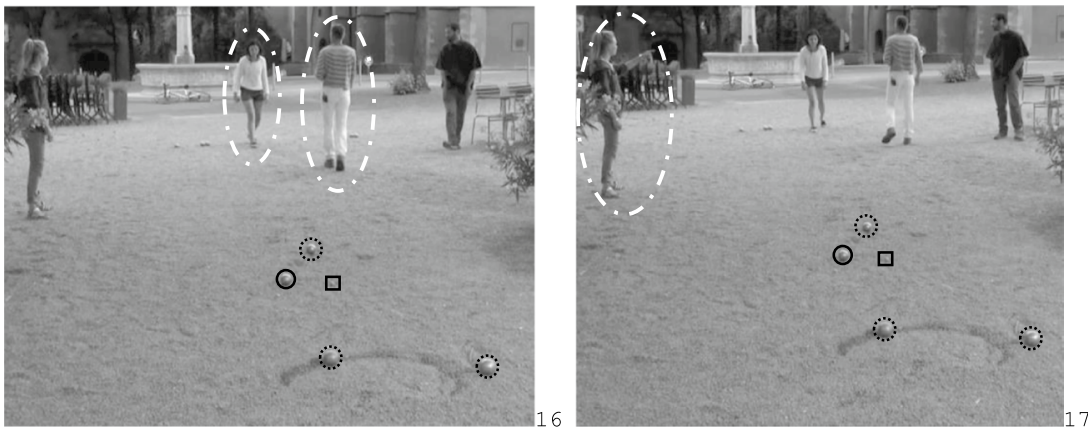


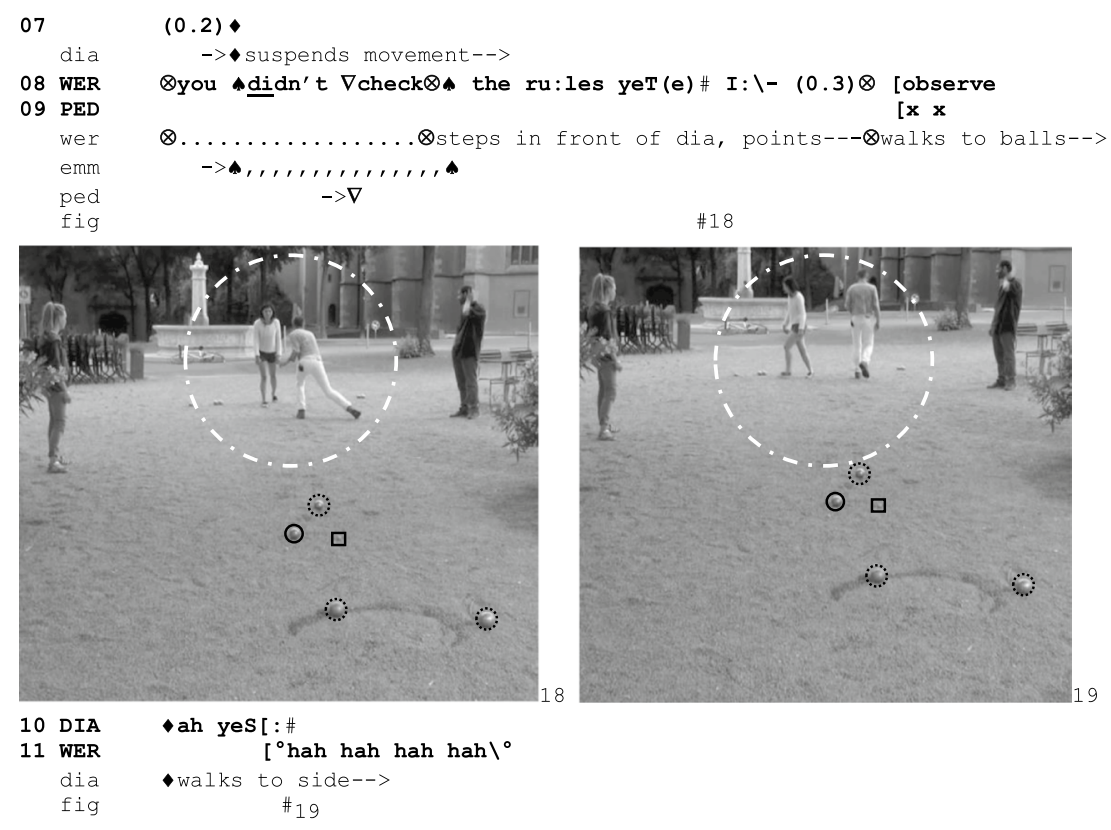

After Pedro's throw but while the ball is still rolling, first Werner and then Pedro displays an understanding that player change is relevant next. Whereas Werner initiates walking towards the throwing circle (1), Pedro steps out of it (2) and walks to the side (4) even before the ball has stopped. By stepping out of the throwing circle, Pedro manifests that he will not continue to play, regardless of the outcome of his throw. Werner, on the other hand, monitors the throw, allowing for the early anticipation that the throw will not result in their team obtaining a leading position (figure 14). When Werner initiates walking forward, Pedro's ball has already passed its possibly closest positioning with reference to the target ball and it is still rolling further (figure 15). This accounts for Werner's embodied projection that their team will continue to play but that they will change player.

As the ball stops (5), Diana picks up one of her team's balls and starts moving towards the throwing circle and prepares to throw (5, figure 16). In this way, she displays an understanding that Pedro leaving the throwing circle makes relevant not only player change but team change, and she progressively projects to play next. It is noteworthy that Diana does not treat Werner walking towards the playing circle as projecting to play next. In this way, Werner and Diana manifest conflicting understandings of the rule concerning who plays next.

As Diana picks up a ball, Emma looks first at Werner and then at Diana (5). Yet, it is only when Diana steps into the throwing circle that Emma treats it as projecting to play next (see Extract 2). This shows that the players' movements within the overall 
play field are monitored and inspected for their possible game relatedness. As Diana progressively projects throwing, Emma produces a negative polarity marker (6, "näe," "no") and points to the members of the other team (6, figure 17). Like in Extract 2, the negative polarity marker indexes Diana's initiated course of action as problematic, while pointing to the other team indicates the solution to the problem and which team should play next (see also Goodwin 2011). In anticipating and correcting Diana's imminent breaking of the rule of who plays next, Emma reflexively establishes this organization as significant for the progression of the activity and, accordingly, as a constitutive expectancy of playing this game.

Diana establishes Emma's correction as sequentially implicative by suspending her preparation in a just-about-to-throw-posture (7, figures $17 ; 18)$. Werner subsequently produces a noticing of Diana's imminent breaking of a rule by means of a negative formulation of her knowledge about the rules, and suspends his walking trajectory and takes a step to his left, positioning himself between the throwing circle and the target ball (8, figure 18). As such, his body forms an obstacle, physically hindering Diana to play. By referring to rules as rules and to their "check-ability," Werner refers to the deontic aspect of engaging in game-playing and holds Diana responsible and accountable for the emerging problem. In this way, he invokes players' obligations to be aware of and act in accordance with the situated expectancies of the unfolding game (see "own-ability," Sharrock 1974). The temporal reference "yet" moreover indicates rules as something that can be acquired over time.

Diana acknowledges the correction by stepping out of the throwing circle and producing an aligning confirmation token (10). Werner, on the other hand, resumes his trajectory and picks up three balls while laughing (9-10, figure 19). In this way, he confirms the distribution of player-ship within his team, where Pedro plays his balls before Werner, an organization which reflexively establishes their respective competence in playing, Werner claiming to be the more experienced player.

When Diana walks towards the throwing circle, she does not display what rule she applies for the organization of next-player-ship. A possible rule formulation is that the-team-that-is-furthest-from-the-target-ball-plays and that she assesses Pedro's throw to be closer than the currently closest ball. Other possible formulations are the-team-that-is-closest-to-the-target-ball-plays, or team-changes-at-everysecond-throw. This shows that the rationale for the participants' moves within the game space is ambiguous with respect to their explicit or propositional formulation. Werner's account for Diana's imminent breaking of a rule nevertheless establishes "knowing how to play" as a publicly observable use of rules at a relevant point in time (see Ryle 1949; Wittgenstein 1958).

In the last two extracts, the emerging problem involved a "wrong" player moving towards the throwing circle, projecting to play next. In the next extract, we focus on an instance in which Diana stays in the throwing circle after her throw and projects to make a second throw. Emma and Diana are playing against Werner and Pedro. 
Extract 4. this is_much better_so it's their turn 050617_00.28.42
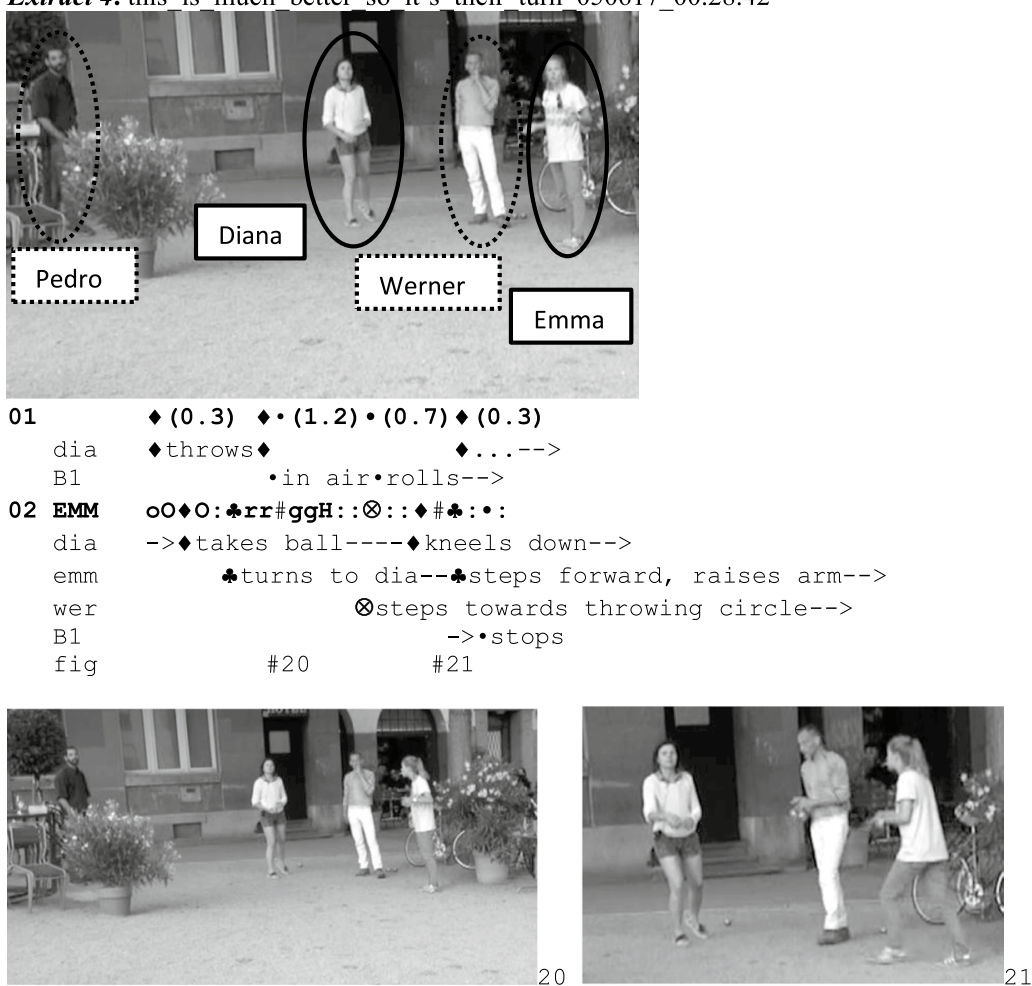

03

05 DIA

$(0.4)$

thi s is much bet $\otimes \bullet+t: \#$ eRr: $:$ : [::
$[$ tttsch: :

wer

emm

emm

fig
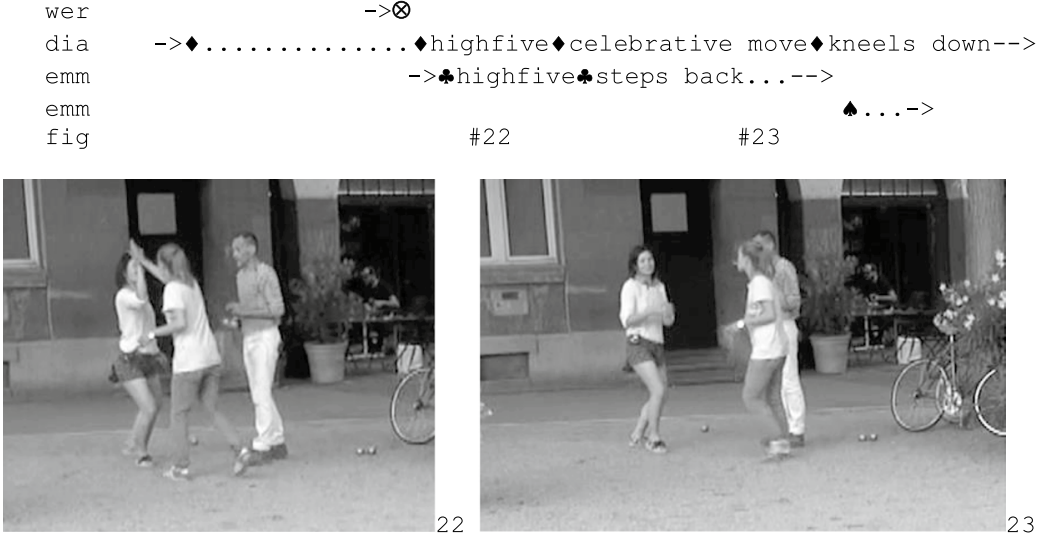

06 EMM

Aso it's *th\#Eir tiame

emm spoints to dia------->

emm

fig

$->+$

\#24 

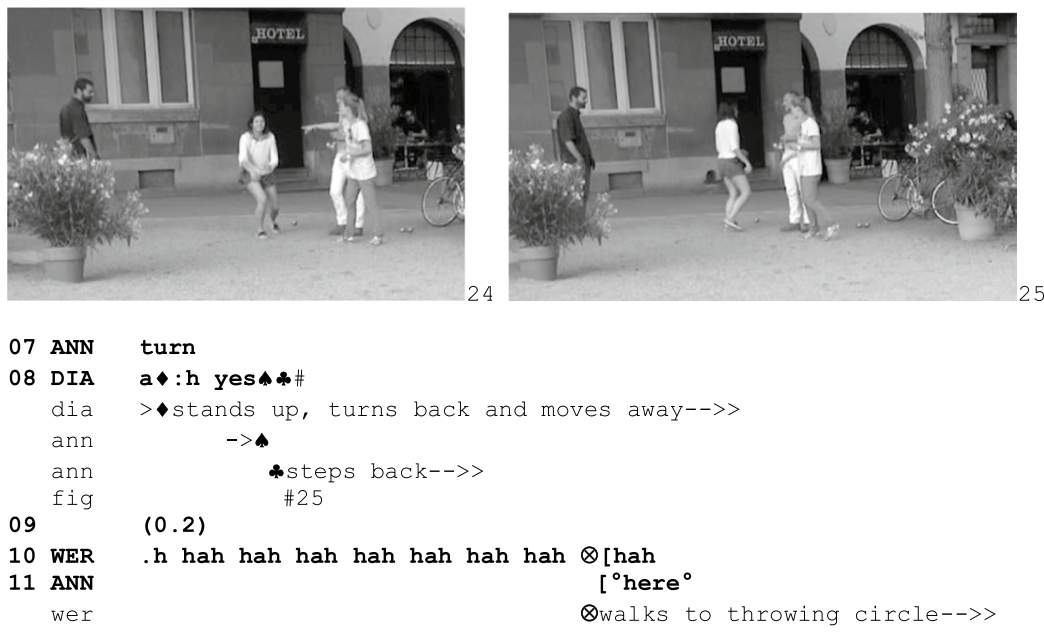

As Diana's ball rolls, her team mate Emma produces a response cry (2), treating it as a good throw and projects a positive outcome, implying team change. Nevertheless, at the beginning of the response cry, Diana takes another ball (figure 20) and kneels down, projecting to make another throw. Meanwhile, Emma steps towards Diana and raises her arms, and Werner walks towards the throwing circle (figure 21). In so doing, two participants, from two different teams, project to be the next players, displaying their respective and conflicting understandings of the progression of the game. Emma initiates a high-five in a celebrative manner, thus recognizing the better outcome. Moreover, this action both suspends Diana's imminent preparation to throw and physically blocks Werner's trajectory to the throwing circle (figure 22). While Emma and Diana engage in the highfive, Werner formulates the outcome of the throw: "this is much better" (4). In this way, both Emma and Werner imply the relevance of team change. Through the turn-final address term, Werner marks Diana's projected player-ship as problematic and disaligns with it (Lerner 2003; Tekin 2019).

At the completion of the high-five celebration, Emma steps back while Diana kneels down (figure 23), resuming her preparation to throw for another time. Emma treats Diana's projection to throw as erroneous by formulating the implication of Werner's prior result formulation, as well as pointing towards Diana (6, figure 24). Whereas the pointing indexes the problem, her utterance provides a solution to it. More specifically, in formatting her utterance as an increment to Werner's utterance with a turn-initial "so," the two utterances complement each other and develops into a rule formulation. Whereas Werner's prior formulation invoked a rule - if the rule is known - Emma's increment complements and 
explicates it. In this way, rule formulation is mobilized as a practice to indicate and correct the imminent breaching of a rule concerning who plays next. This shows that the rule that applies to this specific situation in the game is made explicit in a stepwise, sequentially organized procedure by different persons, revealing its social and interactional character as it is being talked into being.

Diana recognizes and acknowledges the corrections by producing a change of state token (line 8). While doing so, she straightens her body, turns back and moves away from the throwing circle (figure 25). Werner produces some laughter (line 10, see Extract 3), and moves into the throwing circle to play.

In the next extract, we focus on another case in which a player stays in the throwing circle after making a first throw, projecting to play again, and eventually making another throw. In this game, Christian, Emma and Stefan play against Pedro, Diana and Werner.
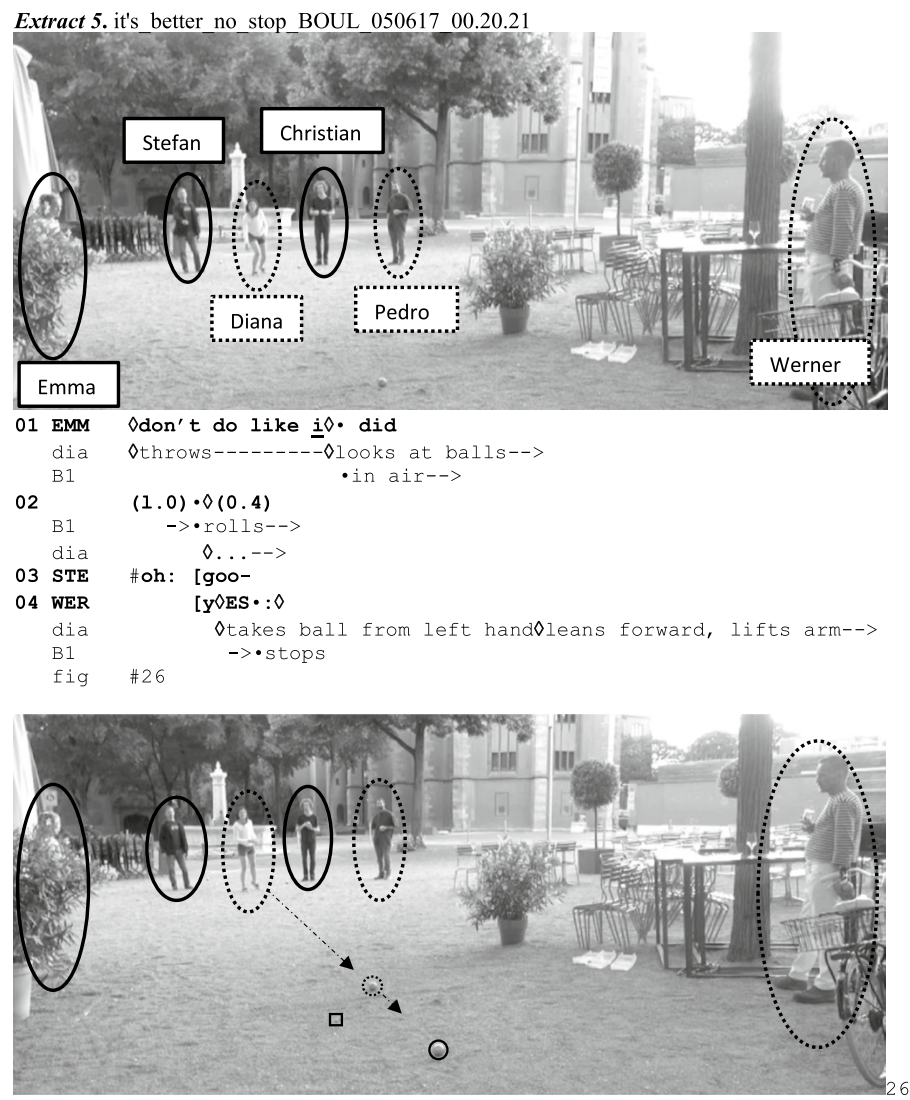

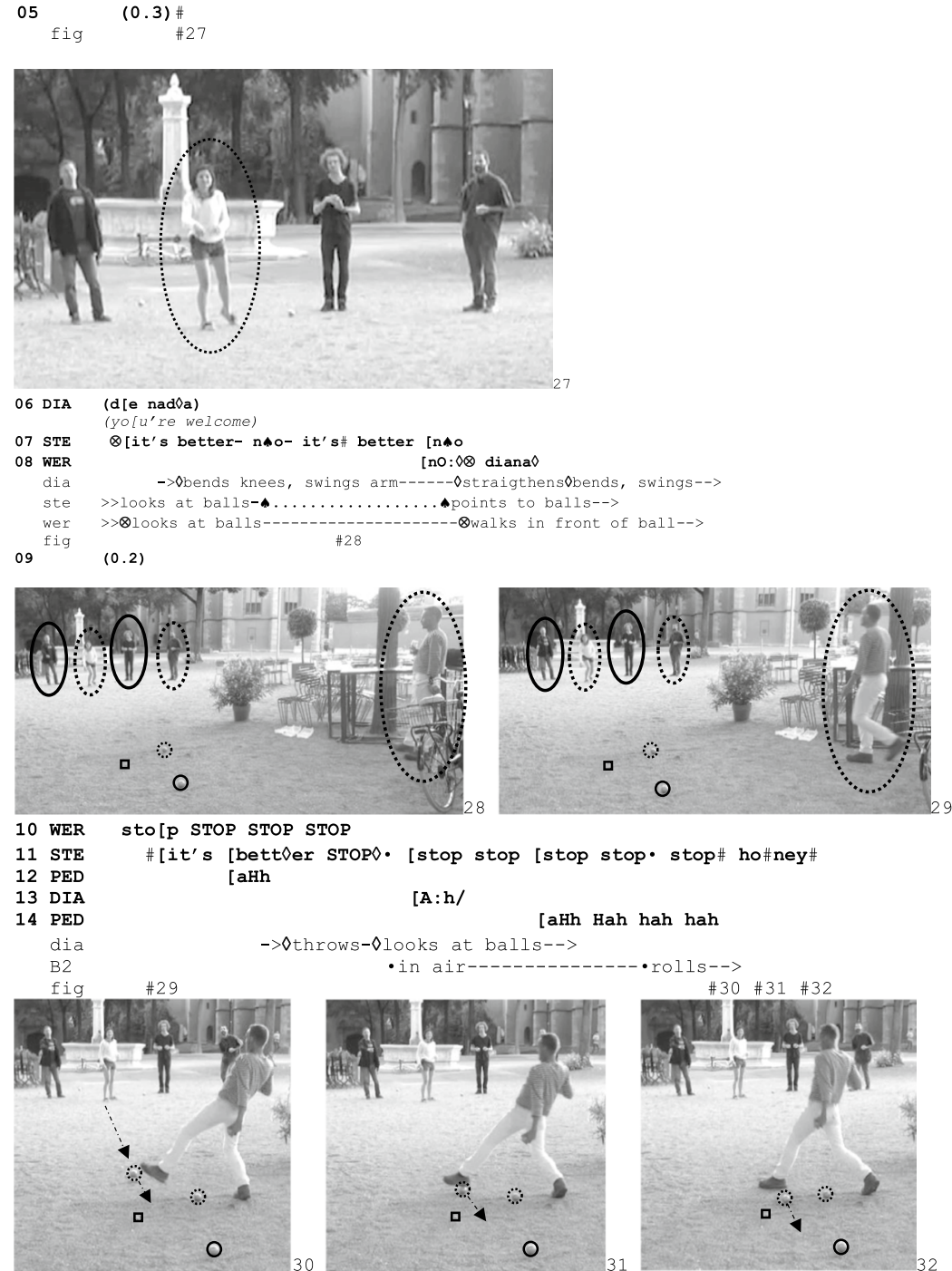

15 DIA 16 PED

wer B2

@Aa@h hah hah thah hahes [hah 'hah hah

$$
\text { [. hieah }
$$

[aHh Hah hah hah

$$
[\mathrm{A}: \mathrm{h} /
$$

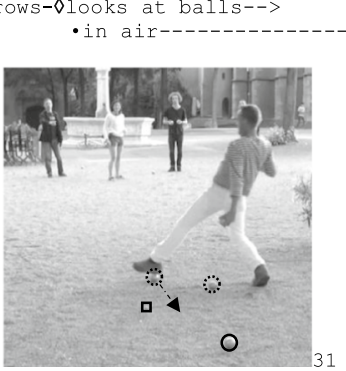

rolls-->

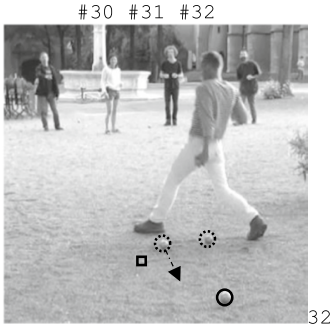

$->$ Qlooks for balls, steps back-->

$\rightarrow \cdot$ stops

$\otimes$ now we have to take that awa [y]

$$
\text { -> } \text { hands to face-> }
$$

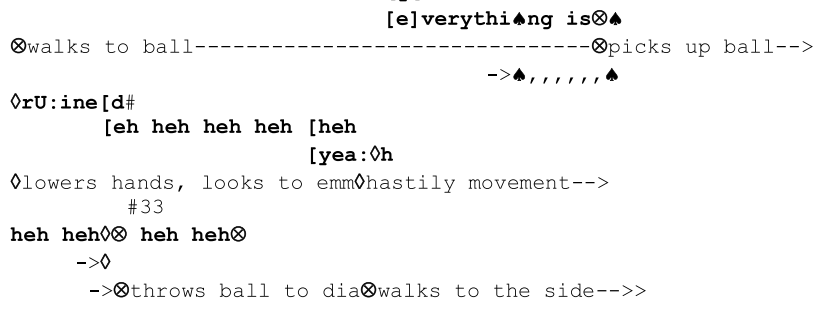



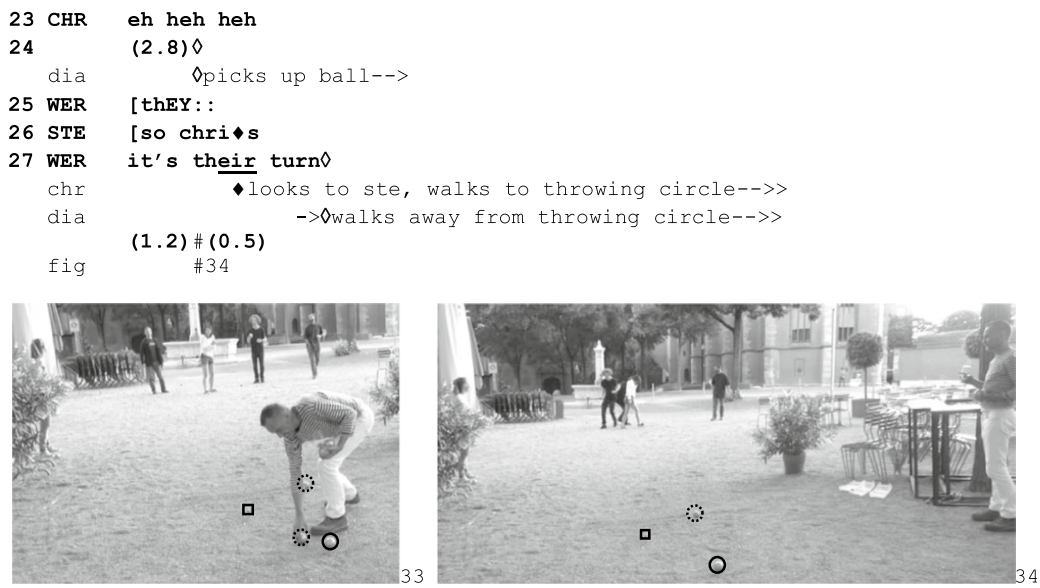

Diana's throw prompts two players from different teams to produce positive assessments while the ball still rolls, anticipating a positive outcome of the throw $(3,4)$. As the ball stops, it is the closest ball to the target ball (figure 26). This means that Diana's team takes the lead, which implies team change. However, just before the ball stops, Diana takes the ball in her other hand, leans forward and raises her arm, projecting to play again (4-5, figure 27). Though she recognizes the outcome of her first throw as a good throw (6), she does not orient to a good throw as implicating team change.

As Diana prepares to throw again by bending her knees and swinging her arm with the ball (figure 28), Stefan corrects the projectable rule violation by formulating the outcome of the throw and producing a negative polarity marker (7, see also Extract 4). As Diana pursues her preparation to throw by bending her knees and swinging her arm, Stefan repeats the outcome formulation and the negative polarity marker whilst also pointing to the game (7). Werner also produces a negative polarity marker and an address term, starting to walk towards the thrown balls (8), and both Werner and Stefan pursue their initiated corrections through repeated imperatives to "stop" $(10,11)$. Werner moreover moves forward and positions himself between the player and the balls already thrown (8, figure 29). As Diana nevertheless throws again (11), Werner seeks to physically block it before it reaches the other balls on the ground, orienting to a possibility of altering the balls' current positioning (figures 30, 31, 32). The participants orient to the publicly available and progressive character of Diana's imminent throw. This projectability is reflected in the ways that they format their utterances, starting with outcome formulations and negative polarity markers, continuing with repeated stop instructions, and finally by engaging physically in preventing the throw and its possibly irreversible consequences by obstructing the ball from reaching the previously thrown balls on the ground. 
While Diana does not treat the initial outcome formulations as relevant for her initiated course of action (concerning rules for who plays next), the resources incrementally deployed by Werner and Stefan (i.e., repeated stop imperatives and walking in front of the balls) retrospectively reveal that the outcome formulations concerned rule usage as opposed to, for instance, its success. Diana's late recognition of breaking a rule is embodied in her outcry right after having thrown the ball (13) and her subsequently laughing and hiding her face in her hands (15). While Werner did not manage to hinder the trajectory of the ball (see figure 32), he picks it up and throws it back, ultimately rejecting its acceptability as a legitimate move in the game (18-22, figure 33). Concurrently, Stefan verbalizes the need to retract the throw (17). Emma, on the other hand, treats the reactions as exaggerated by making an ironic formulation of the consequences of the throw (18-19). Pedro, Diana and Christian treat the dramatized situation as laughable $(16,20,22,23)$. While Werner provides a solution to the practical problem of who plays next by indicating that "it's their turn" $(25,27)$, Stefan produces an address term (26) which Christian hears as selecting him as the next player as he moves towards the throwing circle. Meanwhile, Diana picks up her ball and leaves the throwing circle, aligning with the correction (figure 34).

In the next extract, Emma and Diana play against Werner and Pedro. Diana's team played the first ball and it is still the closest one to the target ball. At the beginning of the game, Werner declared a distribution of labour in their team, proposing that Pedro plays first and try to position his balls as close as possible to the target ball, whereas Werner who is more experienced plays later so he can "kick" away the other team's balls if needed. Subsequent to his first throw, Pedro left the throwing circle, displaying an understanding that the outcome of his throw implied player change and eventually team change. However, Werner indicated that Pedro should throw again and Pedro prepares for his second throw. We join the interaction as Werner starts to walk away from the play field to the café in the back. Meanwhile, Diana is juggling with her balls, and Emma is looking at Pedro. 
Extract 6. it's still eh $050617 \quad 00.27 .58$

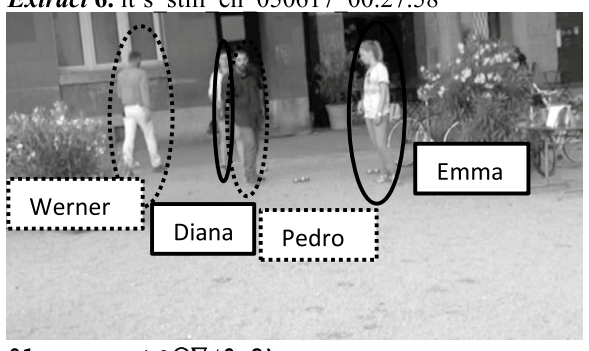

01

$\leftrightarrow \otimes \nabla(0.2)$

dia $\bullet>j u g g l e s$ balls-->

emm $\quad$ looks towards ped-->

wer $\otimes>>$ walks away-->

ped $\quad \nabla$ throws-->

02 DIA mmh

$(0.1) *(0.2)$

emm $\quad->$ looks at balls-->

04 DIA $\mathrm{mh} \mathrm{mh}$

05

$(0.4) \nabla(0.1) \cdot(0.4) \otimes(0.2)$

ped $\quad->\nabla$ looks at balls-->

B1

wer

06 DIA

wer

$\otimes \mathrm{mh}=$

-rolls-->

Qturns towards balls-->

07 PED $=\nabla \leftrightarrow \mathrm{ah}: \otimes$ : even \# [wor $\nabla \cdot \mathrm{se} \otimes$

08 DIA

ped

emm

wer

B1

fig

$\left[\mathrm{mh} \mathrm{mh} \mathrm{(0.3)} \mathrm{\#} \mathrm{mh}+\mathrm{mh}(0.7) \nabla \div{ }^{\circ} \mathrm{mh} \#(.) \mathrm{mh}^{\circ}\right.$

$\nabla$ steps back--------- Vwalks to side--------- Vlooks to emm and dia-->

- puts cigarette in mouth-------- walks to mar looks around-->

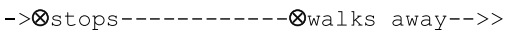

\#35 $\quad$ \#36

\#37
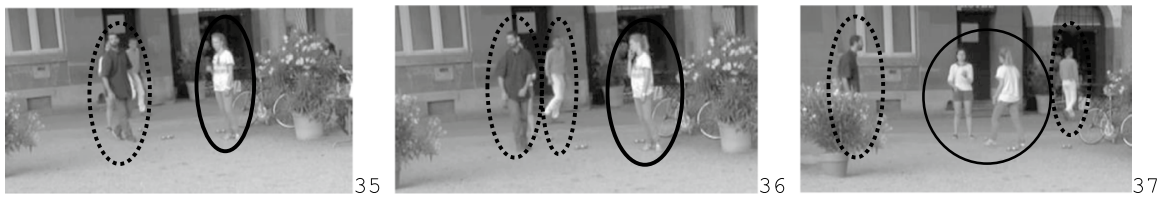

09

$(0.7)$

10 DIA ${ }^{\circ} \mathrm{mh}^{\circ}$

11

$(1.0) \bullet(0.3) *(0.5)$

$\rightarrow$ looks towards balls-->

$->$ looks at dia-->

12 EMM

13 DIA

dia

do you have [fire

$[\mathbf{x x}$

14

$->$ walks towards throwing circle-->

$(0.4) \#(0.1) * \nabla(0.6) \#(0.1)$

-> follows dia's walking trajectory, turns back-->

emm

ped

fig

$->\nabla$ takes one step forward-->

\#38 \#39

15 EMM it's *still* eh:: $:$ : [>it's<*\#sti:»1]-

16 PED

17 EMM

[shall i do a [g»ain

[yeh

emm

ped

dia

fig

$->+\ldots .+$ *..points to pedro*,, , looks around-->>

$->\nabla$ picks up a ball on the ground-->

$->$.... looks back-->

$\# 40$ 

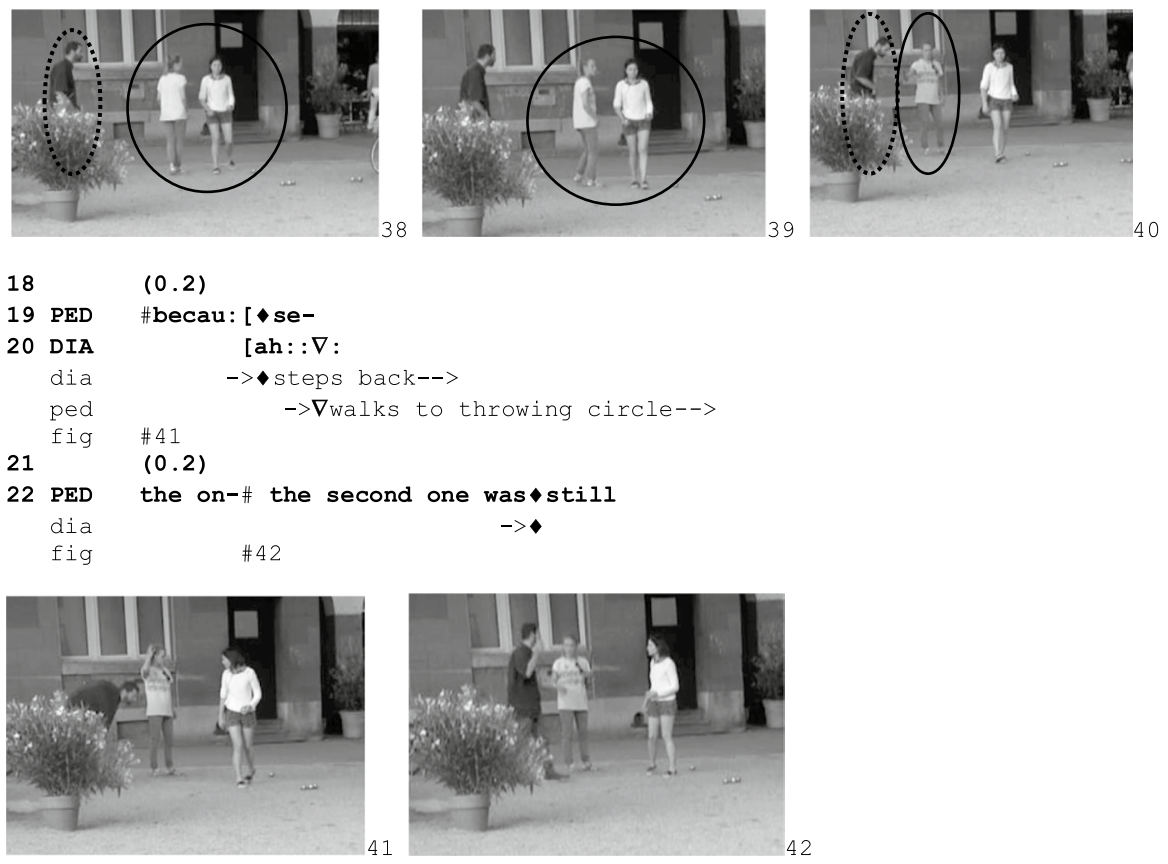

24 PED $\nabla$ very bad ped $\quad \nabla$ throws $-->>$

After Pedro's throw (1) and as the ball touches the ground and begins to roll (5), Werner, who is walking away, turns, stops and monitors the throw (5). As the outcome emerges, Pedro produces an assessment, projecting it to be "even worse" (7), comparing this throw with his previous throw. Although his previous throw implied team continuation and he assesses this throw as worse, he leaves the throwing circle (8, figure 35), projecting player change. Werner resumes however walking away (8, figure 36), projecting that he will not play next and, in accordance with the turntaking rules and their previously established distribution of player-ship within their team, implicitly leaving the only option of next-player-ship to Pedro who still has one ball left.

As the ball still rolls, Emma puts a cigarette in her mouth, walks to Diana and asks for a lighter (12), displaying an understanding that their team will not play next. Diana does not orient to the request, but instead stops juggling her balls, and walks towards the throwing circle (13, figure 38). In this way she treats Pedro leaving the throwing circle as implying team change and projects to play next. As Diana walks forward, Emma visibly monitors her walking trajectory (figure 39), and orients to Diana's walking towards the throwing circle as projecting to break a rule. As Diana 
enters the throwing circle, Emma corrects her understanding of being a legitimate next player by stating that it's still the other team's turn to play and by pointing to Pedro (15, figure 40).

After leaving the throwing circle, Pedro looks to Emma and Diana alternatively, manifestly inspecting their undertakings as relevant for who plays next (8, figure 37). In overlap with Emma correcting Diana's projected player-ship, he kneels down and grabs a ball from the ground, while asking whether to make another throw (line 16, figures 40, 41), which Emma confirms in overlap (17). The format "shall I do again," can be heard both as requesting confirmation and as an offer. In this way, it displays him reviewing his prior understanding of who should play next and recognizing Diana's initiated course of action as potentially problematic.

Subsequent to Emma's correction and Pedro's question about player-ship, Diana suspends her walking and begins to look back (17, figure 41). As Pedro initiates an account for why he should play again (19), Diana steps back (figure 42) and produces a change of state token (20), recognizing and aligning with the correction, occasioning Pedro to start walking towards the throwing circle with a ball in his hand (figure 42), projecting to play next. His account, in past tense, formulates the outcome of his throw as "still" (21) being "very bad" (24), and explicates his reasoning while displaying that he knows the relevant rule to apply in this situation in the game.

In this section, we have seen that the participants recurrently orient to embodied actions in the game environment as projecting to break rules of taking turns at play by means of vernacular corrective practices, including formulating the current situation in the game and/or proposing solutions to the emerging problems. While the prospective suspensions of initiated problematic trajectories invoke rules in implicit ways, the players also use rule formulations as a means to account for the corrections, that is, soliciting and explaining their rationale.

\section{Subsequent Orientations with Explicit References to Rules}

In some cases, the correction sequences of problematic conduct are expanded, in which participants provide reflections on and explicit references to rules as rules. The continuation of Extract 6 is a case in point. After Diana projected to throw again, she was corrected, and Pedro in the other team has thrown the next ball. As he walks away from the throwing circle, Diana explicates a lack of understanding the rules, prompting some explanations of them. 
Extract 7. (continuation of Extract 6)

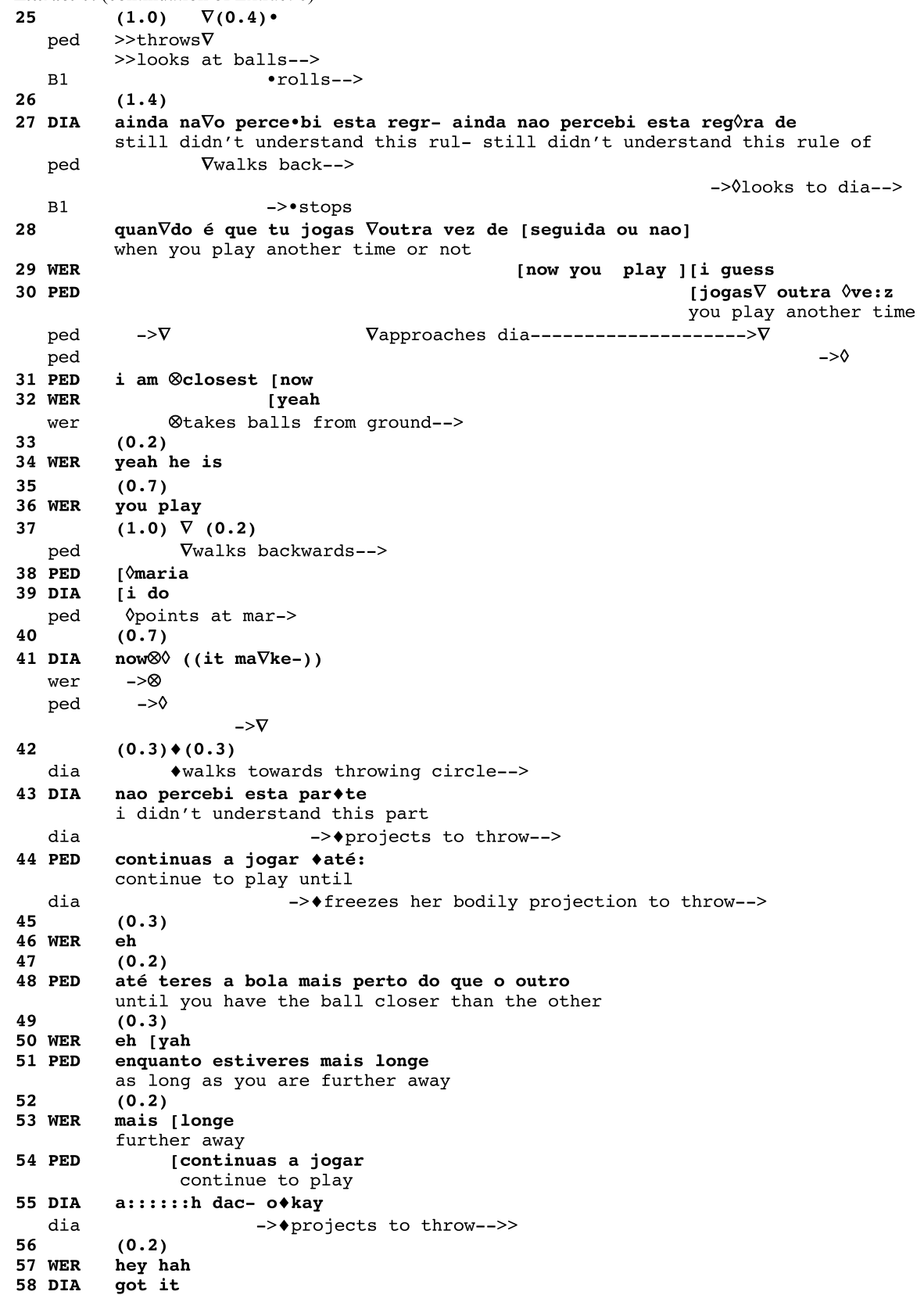


Diana's claimed lack of understanding about the rule concerning throwing another time (or not) is addressed to Pedro in Portuguese (27-28). It explicitly orients to players taking turns, including her previous projection to throw and the related corrections of it (see Extract 6) as governed by rules, which participants are presumed to have knowledge about. In this way, she treats rules as an understandable and applicable phenomenon. Moreover, she addresses their acquirable aspect over time, as she acknowledges that she "still" has not understood the rules for player alternation (27). Yet, this has not precluded her from engaging in the game. Manifestly, one can play the game without fully understanding, or knowing (how to apply) its rules (see Sharrock and Button 1999; Wittgenstein 1958).

As Pedro responds to Diana (30), projecting a rule formulation or explanation, Werner comes back to the playing field and selects Diana to play next (28-29). This shows his understanding of the current situation of the game, the exchange between Diana and Pedro, as well as Diana not projecting to play next, as indicative of an issue of who plays next. Pedro suspends his explanation of the rule, and proposes an explanation of Werner's other-selection (that the closest team does not play but the other one, 31), switching to English. As such, both Werner and Pedro orient to the relevance of progressing with the game. Though Werner produces some confirmation tokens $(32,34)$, this does not prompt Diana to project playing (e.g., walking towards throwing circle), which occasions Werner to insist that "you play" (36). Although Diana aligns with being selected as the next player by walking towards the throwing circle and projecting to throw by swinging her arm with the ball, she pursues her claim of not understanding the rule (43). This prompts Pedro to produce a rule formulation in the form of an instruction: "continue to play until you have the ball closer than the other" (44-48). With no uptake from Diana, Pedro goes on to formulate the rule in another way: "as long as you are further away, continue to play" (51-54). Diana produces an elongated change of state and confirmation token (55) and explicitly asserts understanding (58), thus claiming that she now plays as a player applying a relevant rule in the game.

Another case in point is the continuation of Extract 3, where Pedro left the throwing circle after throwing, giving place for his team mate Werner to throw next. As Diana in the other team also projected to play next, she was corrected, prompting her to leave the throwing circle again. As she walks over to her teammate Emma, she explicates that she does not see the rationale behind the organization of player alternation. 


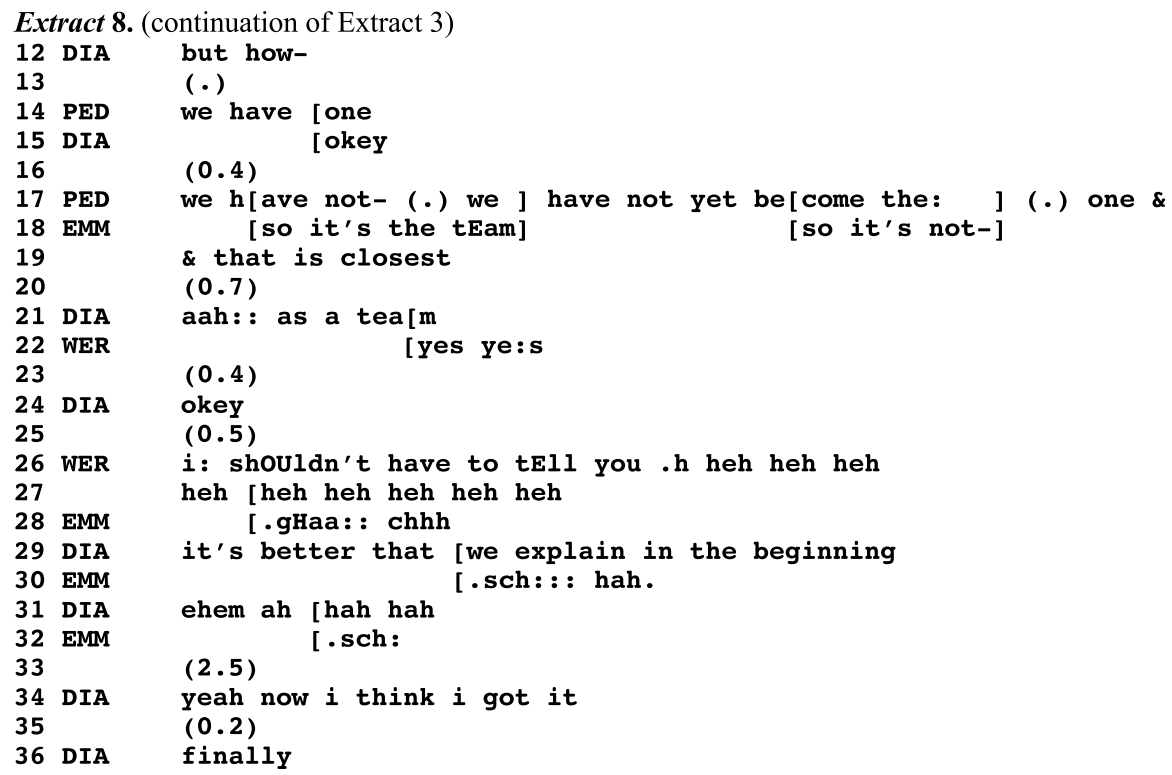

In response to Diana's initiated but abandoned inquiry (12), Pedro and Emma propose two different yet complementary explanations of the rule applying to the just prior game situation. Whereas Pedro addresses the issue of a thrown ball's closeness to the target ball as consequential for team and player change (17-19), Emma refers to teams - as opposed to persons - as relevant parties for turn alternation (18). Diana retrospectively confirms her prior problem of understanding by explicating a change of state through "ah" and a partial repeat of Emma's explanation (21). Werner treats this explicated problem as contestable by resorting to deontic aspects of rules. By claiming that he "shouldn't have to tell" Diana about the organization of turn alternation, he treats knowing when to play as a responsibility on behalf of the players and even a premise for playing, thereby holding Diana accountable for not knowing the rule (26). Whereas Emma resists this accusatory complaint by vocal expressions $(28,30,32)$, Diana counters Walter's claimed attribution of responsibility by referring to the instructive aspect of rules, which should be explained "in the beginning" (29). She subsequently formulates a mitigated claim about having understood the rule "now" (34), followed by a retrospective reflection, "finally" (36), which both treats rules as being acquired over time and publicly recognizes her prior problems with knowing the rules.

In this section, we have seen that participants treat rules as acquired over time, and that they engage in playing the game without necessarily knowing the rules. As such, rules are a matter of knowledge in the sense of understanding how to use them, and the rationale of the organizational aspects of playing that amounts to the game pétanque. Moreover, participants treat the use of rules as a moral issue that is related to issues of rights and obligations, not only knowing the rules but also explaining their use at play. 


\section{Conclusions}

This paper demonstrates that the participants of the game playing activity treat the normative aspects and orders of the game as being embedded in the know-how of playing. The amateur aspect of the playing activity occasions situations where the constitutive expectations of the game are breached. This is recognizable in the recurrent displays of problems of knowing what is relevant to do next and the sanctions in form of corrections that they prompt, including through rule formulations. As players make moves that break the basic rules of the game, the seen but unnoticed features of the activity, as they apply to members' conduct, are seen, noticed and made accountable (Garfinkel 1963, 1967, 2019). Our empirical analysis reveal that emerging problems of projectable rule violations are identified and solved through ordinary interactional practices of natural language with recurrent features. Incipient violations of rules prompt noticings, corrections and instructions, which invoke and reflexively establish the constitutive expectations that constitute this particular game.

The corrections are initiated with negative polarity markers, formulations of the current state of the game, and formulations of solutions to the projectable problems. They are often formatted with repeated imperatives, deictics, and pointings. The sequential analysis of the participants' conduct shows that the multimodally composed practices of denouncing a move in the game as problematic, are contingent on the nature of the trouble source (projecting to play next or to play again). The players treat moving towards the throwing circle or staying in the throwing circle while holding balls as an orientation to using rules that concern who plays next. The projectability of these aspects are contingent on spatial configurations and afford different temporal frameworks for initiating action trajectories that makes the recognizability of projecting to play next publicly available. Indeed, the players anticipate and engage in correcting projectable violations of the rules, before they are done, which shows their close monitoring and situated understanding of the activity as normatively ordered and sequentially organized. The players manifestly monitor bodily trajectories and inspect courses of action within the game as relevant for the progressivity of the game according-to-a-rule. As an illegitimate player projects to play by being in the throwing circle, this does not only imply a misunderstanding of who plays next, but also hinders a legitimate player to play next. However, while the majority of the corrections sequences in this study concern projectable rule violations, it is crucial to note that even in the case where the erroneous throw is completed and the rule for who-plays-next is obviously transgressed (see Extract 5), this is not subjected to sanctions such as disqualifying the player or giving penalties (see Sacks 1992). Instead, Diana's thrown ball is taken away and the relevant next move in the game is made for another first time. Moreover, several players from different teams engage in correcting projectable rule violations even when an incorrect throw would be strategically beneficial for the correcting party. These observations indicate that participants principally orient to playing the game according to the rules as a collective and joint social activity. These corrective practices have the structural and organizational characteristics of side sequences that are manifestly recognized as doing correcting (Jefferson 1972; Svensson 2020). This shows that the 
participants treat embodied trajectories that depart from the situated expectancies as problems of understanding the procedure for using the rules of taking turns at play. The progressively elaborated formats of the correcting practices further show that they reflexively establish and conform to the situated expectancies that make up the recognizability of doing correcting (Garfinkel 1963; Garfinkel and Sacks 1970).

The observations about the locally produced order of turn alternation also concerns the prospective character of situated social activities. Participants manifestly monitor game conducts for their conformity with the rules, allowing that embodied trajectories which are seen as projecting to break the rules are identified and rectified, sometimes even before the action is produced. In this way, the players do not play by the rules but with the rules (see Goodwin 1995). This implies that the relevance of rules is not strictly dependent on the outcome of the game, but that participants engage in work to pre-empt the rule breakings by implying and invoking them. While rule formulations can be used to account for actions, they are not always temporally placed after the completion of the actions. Rule formulations are produced as a last resort, only after other resources for hindering the problematic trajectory. In this way, formulating rules is a practice for indicating and correcting incipient violations of the situated expectancies concerning who plays next.

One does not need to wait and see the result of initiated conduct within the game in order to judge their acceptability and legitimacy as game relevant actions. A player can throw the ball when instructed to, thereby playing according to a rule, while not being able to account for the rationale behind the rule or even the possible consequences for breaking a rule. It is noticeable that although (projectable) rule violations are treated as invalid and are corrected, they are not treated as done with an intention to cheat, for example, but as a consequence of lack of knowledge about the rules (see Goodwin 2006 on knowingly violating and playing with the rules). This resonates with Wittgenstein's (1958) observations concerning rule usage as a relevant application of a specific procedure in a specific situation. Garfinkel (1963) claims that complying with the "constitutive order of events" is the very premise for people to engage in situated activities and sustain social order. The participants engage in game play and they treat their respective undertakings as inspectable for their game relevance. Natural language is the fundament for recognizably doing just that, including coming to terms with emerging problems in the game as they are treated as problems of intersubjectivity. The very intelligibility of these procedures is constituted by the sequentially organized, situated accomplishment of social practices. Rules are not prescriptions of game conduct, but resources that reflexively render the players' respective actions intelligible as playing that game into being.

Acknowledgements We are grateful to the persons participating in this study. We thank Lorenza Mondada for her comments.

Funding Open Access funding provided by Universität Basel (Universitätsbibliothek Basel). This study was supported by the FiDiPro Project "Multimodality: Reconsidering language and action through embodiment," funded by the Academy of Finland and the University of Basel. 


\section{Declarations}

Conflict of interest Authors declare that they have no conflict of interest.

Consent to participate All participants consented to participate in this study.

Open Access This article is licensed under a Creative Commons Attribution 4.0 International License, which permits use, sharing, adaptation, distribution and reproduction in any medium or format, as long as you give appropriate credit to the original author(s) and the source, provide a link to the Creative Commons licence, and indicate if changes were made. The images or other third party material in this article are included in the article's Creative Commons licence, unless indicated otherwise in a credit line to the material. If material is not included in the article's Creative Commons licence and your intended use is not permitted by statutory regulation or exceeds the permitted use, you will need to obtain permission directly from the copyright holder. To view a copy of this licence, visit http://creativecommons.org/licen ses/by/4.0/.

\section{References}

Bennerstedt, U., \& Ivarsson, J. (2010). Knowing the way. Managing epistemic topologies in virtual game worlds. Computer Supported Cooperative Work (CSCW), 19, 201-230.

Coulter, J. (2009). Rule-following, rule-governance and rule-accord: Reflections on rules after Rawls. Journal of Classical Sociology, 9(4), 389-403.

Garfinkel, H. (1963). A conception of, and experiments with, 'trust' as a condition of stable concerted actions. In O. J. Harvey (Ed.), Motivation and social interaction (pp. 187-238). Ronald Press.

Garfinkel, H. (1967). Studies in ethnomethodology. Prentice-Hall.

Garfinkel, H. (2019). Notes on language games as a source of methods for studying the formal properties of linguistic events. European Journal of Social Theory, 22(2), 148-174.

Garfinkel, H., \& Sacks, H. (1970). On formal structures of practical action. In J. Tekinney \& E. A. Tiryakian (Eds.), Theoretical sociology (pp. 337-366). Appleton-Century Crofts.

Garfinkel, H., \& Wieder, L. D. (1992). Two incommensurable, asymmetrically alternate technologies of social analysis. In G. Watson \& R. M. Seiler (Eds.), Text in context: Contributions to ethnomethodology (pp. 175-206). Sage.

Goodwin, C. (2011). Contextures of action. In J. Streeck, C. Goodwin, \& C. LeBaron (Eds.), Embodied interaction (pp. 182-193). Cambridge University Press.

Goodwin, M. H. (1983). Aggravated correction and disagreement in children`s conversations. Journal of Pragmatics, 7(6), 657-677.

Goodwin, M. H. (1985). The serious side of jump rope: Conversational practices and social organization in the frame of play. Journal of American Folklore, 98(389), 315-330.

Goodwin, M. H. (1995). Co-construction in girls' hopscotch. Research on Language and Social Interaction, 28(3), 261-281.

Goodwin, M. H. (2006). The hidden life of girls: Games of stance, status, and exclusion. Blackwell.

Ivarsson, J., \& Greiffenhagen, C. (2015). The organization of turn-taking in poolskate sessions. Research on Language and Social Interaction, 48(4), 406-429.

Jefferson, G. (1972). Side sequences. In D. Sudnow (Ed.), Studies in social interaction (pp. 294-333). Free Press.

Jefferson, G. (2004). Glossary of transcript symbols with an introduction. In G. Lerner (Ed.), Conversation analysis: Studies from the first generation (pp. 13-31). John Benjamins.

Kew, F. (1986). Playing the game: An ethnomethodological perspective. International Review for the Sociology of Sport, 21(4), 305-321.

Kew, F. C. (1992). Game-rules and social theory. International Review for the Sociology of Sport, 27(4), 293-307.

Lerner, G. H. (2003). Selecting next speaker: The context-sensitive operation of a context-free organization. Language in Society, 32(2), 177-201.

Liberman, K. (2013). More studies in ethnomethodology. State University of New York Press. 
Liberman, K. (2016). Rules as ethnomethods: A case study of the surfers`lineup. Kolding: University of Southern Denmark.

Livingston, E. (2006). Ethnomethodological studies of mediated interaction and mundane expertise. The Sociological Review, 54(3), 405-425.

Livingston, E. (2008). Ethnographies of reason. Ashgate.

Livingston, E. (2012). Games, pastimes, and leisure pursuits. American Sociologist, 43(1), 109-124.

Macbeth, D. (2012). Some notes on the play of basketball in its circumstantial detail, and an introduction to their occasion. Human Studies, 35(2), 193-208.

Moerman, M., \& Sacks, H. (1988). On "understanding" in the analysis of natural conversation. In M. Moerman (Ed.), Talking culture (pp. 180-186). University of Pennsylvania Press.

Mondada, L. (2018). Multiple temporalities of language and body in interaction. Challenges for transcribing multimodality. Research in Language and Social Interaction, 51(1), 85-106.

Rawls, A. W. (2019). Introduction to Garfinkel's 'Notes on Language games': Language events as cultural events in 'systems of interaction'. European Journal of Social Theory, 22(2), 133-147.

Ryle, G. (2009). The concept of mind (60th Anniversary Edition). London: Routledge.

Sacks, H. (1992). Lectures on conversation. Blackwell.

Sacks, H., Schegloff, E. A., \& Jefferson, G. (1974). A simplest systematics for the organization of turntaking for conversation. Language, 50(4), 696-735.

Schegloff, E. A. (1992). Repair after next turn: The last structurally provided defense of intersubjectivity in conversation. American Journal of Sociology, 97(5), 1295-1345.

Schegloff, E. A., \& Sacks, H. (1973). Opening up closings. Semiotica, 8(4), 289-327.

Schegloff, E. A., Jefferson, G., \& Sacks, H. (1977). The preference for self-correction in the organization of repair in conversation. Language, 53(2), 361-382.

Sharrock, W. W. (1974). On owning knowledge. In R. Turner (Ed.), Ethnomethodology (pp. 45-53). Penguin.

Sharrock, W., \& Button, G. (1999). Do the right thing! Rule finitism, rule scepticism and rule following. Human Studies, 22, 193-210.

Sharrock, W., \& Dennis, A. (2008). That we obey rules blindly does not mean that we are blindly subservient to rules. Theory, Culture \& Society, 25(2), 33-50.

Svensson, H. (2017). Scruter et Corriger. L'accomplissement interactionnel de la révision d'une inscription publique. In L. Mondada, \& S. Keel (Eds.), Participation et asymétries dans l'interaction institutionnelle (pp. 203-232). Paris: L'Harmattan.

Svensson, H. (2020). Establishing shared knowledge in political meetings. Routledge.

Tekin, B. S. (2019). Bodies at play. Exploring participation, spectatorship, and morality in videogaming activities. Unpublished doctoral dissertation. University of Basel, Switzerland.

Tekin, B. S., \& Reeves, S. (2017). Ways of spectating: Unravelling spectator participation in Kinect play. In: Proceedings of the ACM CHI Conference on Human Factors in Computing Systems (CHI 2017), pp. 1558-1570. Denver, CO, USA.

Wittgenstein, L. (1958). Philosophical investigations. Blackwell.

Publisher's Note Springer Nature remains neutral with regard to jurisdictional claims in published maps and institutional affiliations. 